TEKNIK, 39 (1), 2018, 62-66

\title{
Analisa Jaringan Perpipaan Distribusi Air Bersih Menggunakan EPANET 2.0 (Studi Kasus di Kelurahan Harapan Baru, Kota Samarinda)
}

\author{
Searphin Nugroho *, Ika Meicahayanti, Juli Nurdiana \\ Program Studi Teknik Lingkungan, Fakultas Teknik, Universitas Mulawarman, \\ Jl. Sambaliung No.9, Kampus Gunung Kelua, Samarinda, Indonesia 75117
}

\begin{abstract}
Abstrak
Distribusi air di Kota Samarinda masih belum optimal dikarenakan factor tekanan air di dalam pipa yang rendah pada waktu tertentu dan kehilangan air fisik karena kebocoran. Artikel ini memuat analisa jaringan perpipaan distribusi air bersih di Kelurahan Harapan Baru, Kota Samarinda menggunakan perangkat lunak EPANET 2.0. Hasil simulasi dibandingkan dengan hasil pengukuran tekanan air di lapangan pada kran pelanggan menggunakan manometer. Dari hasil penelitian, diketahui terdapat sebanyak 7 junction yang nilai tekanan airnya di bawah batas minimum kriteria pipa distribusi dari Peraturan Menteri Pekerjaan Umum No.18/PRT/M/2007 sebesar 0,5 atm, serta sebanyak 11 pipa yang nilai kecepatan aliran airnya di bawah batas minimum kriteria yang sama sebesar 0,3 m/s. Rekomendasi perbaikan jaringan perpipaan distribusi air bersih berupa tekanan minimum sebesar 0,5 bar pada pelanggan dan kontinuitas, yakni perubahan pengaturan tekanan pada valve existing, dan penambahan pompa booster pada beberapa titik. Terdapat perbedaan nilai tekanan air yang cukup signifikan antara hasil simulasi model EPANET dengan pengukuran langsung pada kran pelanggan.
\end{abstract}

Kata kunci: EPANET 2.0; jaringan perpipaan; kebocoran pipa; tekanan air; distribusi air bersih

\begin{abstract}
[Title: Title: Analysis of Clean Water Distribution Pipeline Using EPANET 2.0 (Case Study in Harapan Baru District, Samarinda City)] Water distribution in Samarinda City is not optimal because of low water pressure in pipeline on specific time and physical water losses by leakage. This article presents analysis of clean water distribution pipeline in Harapan Baru District, Samarinda City using EPANET 2.0 software. Simulation results are compared to measurement results of water pressure at field on costumers' faucets using manometer. Research results show that there are 7 junctions, which value of water pressure were below the distribution pipes standard from Regulation of the Minister of Public Works No.18/PRT/M/2007 in the amount of 0.5 atm, along with 11 pipes which value of water velocity below than minimum value $0,3 \mathrm{~m} / \mathrm{s}$. Recommendations for repairing clean water distribution pipes of minimum pressure around 0.5 bar in all customers and continuity, i.e. resetting pressure adjustment of existing valves and adding booster pumps at some places. There were significant differences of water pressure value between the EPANET model simulation result and the measurement at costumers' faucets.
\end{abstract}

Keywords: EPANET 2.0; pipeline; pipeline leakage; air pressure; clean water distribution

\section{Pendahuluan}

Di Kota Samarinda, tidak jarang banyaknya keluhan dari masyarakat mengenai pe nyaluran air bersih ke rumah masing-masing, walaupun pada

\footnotetext{
* Penulis Korespondensi.

E-mail: searphin91@gmail.com
}

kenyataannya PDAM telah melakukan distribusi air bersih selama 24 jam tanpa henti, kecuali pada saat mati listrik. Kasus ini dapat disebabkan oleh beberapa faktor, yang merupakan sebagian kendala yang dihadapi PDAM, yakni tekanan air di dalam pipa yang rendah pada waktu tertentu dan kehilangan air fisik seperti kebocoran pada pipa (PDAM Tirta Kencana, 2015). 


\section{TEKNIK, 39 (1), 2018, 63}

Kelurahan Harapan Baru ialah salah satu kelurahan yang termasuk ke dalam wilayah Kecamatan Loa Janan Ilir, Kota Samarinda. Berdasarkan pengamatan atau observasi langsung di lapangan melalui pengukuran menggunakan GPS, topografi pada Kelurahan Harapan Baru relatif datar, namun pada bagian timur dan selatan cenderung berbukit dengan rentang antara $25-54 \mathrm{~m}$, sehingga terdapat kemungkinan bahwa tekanan air dari instalasi pengolahan air cenderung rendah pada tempat-tempat yang berbukit tersebut. Selain itu, berdasarkan data milik PDAM Tirta Kencana, tingkat kehilangan air di Kelurahan Harapan Baru, berdasarkan data dari DMA (District Metering Area) di area perumahan Grand Tamansari Samarinda pada tahun 2016, yang sebesar 44\%. Hal ini tentunya jauh lebih besar daripada ketentuan Nasional untuk kehilangan air yang maksimal sebesar 20\% dari total produksi air (PDAM Tirta Kencana, 2015). Berbagai permasalahan inilah yang menyebabkan perlu dilakukannya penelitian lebih lanjut terhadap kondisi jaringan perpipaan distribusi air bersih agar dapat segera diatasi serta distribusi air dapat berjalan dengan optimal.

Dalam melakukan analisa jaringan perpipaan distribusi air bersih, dibutuhkan perangkat bantuan untuk mempermudah dalam melakukan analisa. seperti program EPANET 2.0, WaterCad 8.0, dan Pipe Flow Expert 2010. Namun, diantara software-software tersebut, digunakanlah software EPANET 2.0, dikarenakan mudah didapatkan serta tidak memerlukan spesifikasi komputer yang tinggi (Al Amin, 2011). EPANET merupakan sebuah program komputer berbasis Windows yang dikembangkan oleh U.S. Environmental Protection Agency (EPA). EPANET melakukan simulasi hidrolik dan perilaku kualitas air dalam jaringan pipa bertekanan, seperti sistem pasokan air perkotaan. Sebuah jaringan dapat terdiri dari pipa, sambungan pipa, pompa, katup, tangki penyimpanan, dan waduk (Ahmadullah \& Dongshik, 2016). Menurut Ramana, Sudheer dan Rajasekhar (2015), keunggulan dari penggunaan software EPANET 2.0 untuk analisa jaringan distribusi yaitu laju aliran dalam jaringan diperoleh dengan menggunakan metode linear, dan kehilangan tekanan akibat gesekan dihitung dengan menggunakan rumus Darcy-Weisbach atau Manning. Selain itu software ini juga memiliki kemampuan dalam mempertimbangkan minor loses, dapat menduplikasi tuntutan yang bervariasi dari waktu ke waktu, serta dapat menangani pola permintaan yang berbeda untuk setiap node.

Studi mengenai analisa jaringan perpipaan distribusi air bersih telah banyak dilakukan di Indonesia. Selintung, Hatta dan Sudirman (2012) mengevaluasi pemenuhan kebutuhan air dan jaringan perpipaan air bersih di Kabupaten Maros dengan melakukan perbandingan hasil simulasi distribusi air menggunakan software EPANET 2.0 denan hasil pengukuran lapangan melalui pembacaan water meter. Sudarsono \& Nugraha (2013) meneliti tentang pemanfaatan peta tematik untuk menganalisa letak kebocoran jaringan pipa distribusi milik PDAM Kota Demak dengan meng-overlay peta Kota Demak dengan jaringan pipa distribusi air bersih.

Artikel ini memuat analisa jaringan perpipaan distribusi air bersih di kelurahan Harapan Baru, Kota Samarinda menggunakan EPANET 2.0. Analisa meliputi identifikasi faktor-faktor yang mempengaruhi optimalitas distribusi air bersih dari aspek jaringan perpipaan PDAM kemudian memaparkan rekomendasi serta kendala dalam perbaikan jaringan perpipaan distribusi air bersih.

\section{Metode Penelitian}

Metode yang digunakan dalam melakukan analisa terdiri atas beberapa tahapan, yakni: (a) tahap persiapan, dimana dilakukan studi literatur untuk menentukan acuan penelitian serta pengumpulan data primer \& data sekunder; (b) tahap penelitian, yang terdiri dari pembuatan peta jaringan baru dengan bantuan software ArcMap 10.3.1, perhitungan kebutuhan air (base demand), dan pemodelan jaringan perpipaan menggunakan software EPANET 2.0; dan (c) tahap analisa, dimana dilakukan analisa parameter tekanan air dan kecepatan air pada model jaringan perpipaan yang dibuat menggunakan EPANET 2.0 dengan memperhitungan faktor jam puncak, analisa terhadap perbandingan nilai tekanan hasil simulasi model EPANET dengan pengukuran tekanan air pada kran pelanggan, serta pembuatan rekomendasi perbaikan sistem jaringan perpipaan distribusi air bersih dengan menyesuaikan kriteria pipa distribusi berdasarkan Peraturan Menteri Pekerjaan Umum Republik Indonesia Nomor 18 Tahun 2007 (Kementerian Pekerjaan Umum Republik Indonesia, 2007).

Perhitungan base demand dilakukan dengan menggunakan beberapa persamaan yang dapat ditinjau berikut ini:

a. Menurut Komalia \& Indrawan (2013), persamaan untuk menghitung besar kebutuhan air domestik $\left(\mathrm{Q}_{\mathrm{d}}\right)$ adalah sebagai berikut:

$$
Q_{d}=\text { Jumlah penduduk } \times q
$$

b. Menurut Komalia \& Indrawan (2013), persamaan untuk menghitung besar kebutuhan air non-domestik adalah sebagai berikut:

$$
Q_{n}=\text { Jumlah orang atau fasilitas } x \quad q
$$

c. Menurut Hamdani, Sulistio dan Syahputra (2014), persamaan untuk menghitung besar kebutuhan air 


\section{TEKNIK, 39 (1), 2018, 64}

rata-rata harian dengan asumsi besar kehilangan air minimum berdasarkan Tabel 1 yang sebesar 20\% adalah sebagai berikut:

$$
Q_{r h}=Q_{d}+Q_{n}+20 \%\left(Q_{d}+Q_{n}\right)
$$

d. Menurut Ibrahim, Masrevaniah \& Darmawan (2011), persamaan untuk menghitung hukum kontinuitas air di dalam pipa adalah sebagai berikut:

$$
\begin{aligned}
& Q 1=Q 2+Q 3 \\
& A 1 . v 1=(A 2 . v 2)+(A 3 . v 3)
\end{aligned}
$$

$$
\begin{aligned}
& \text { Keterangan: }
\end{aligned}
$$

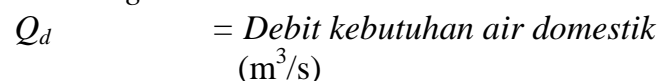

$$
\begin{aligned}
& q=\text { Debit kebutuhan air kriteria } \\
& \text { ( } \ell / \text { orang/hari) dan atau ( } \ell / \text { hari) } \\
& Q_{n} \quad=\text { Debit kebutuhan air non-domestik } \\
& \left(\mathrm{m}^{3} / \mathrm{s}\right) \\
& Q_{r h}=\text { Debit kebutuhan air rata-rata } \\
& \text { harian }\left(\mathrm{m}^{3} / \mathrm{s}\right) \\
& \text { Q1, Q2, Q3 = Debit yang mengalir pada } \\
& \text { penampang 1, } 2 \text { dan } 3\left(\mathrm{~m}^{3} / \mathrm{s}\right) \\
& v 1, v 2, v 3=\text { Kecepatan pada penampang } 1,2 \\
& \text { dan } 3(\mathrm{~m} / \mathrm{s}) \\
& \text { A1, A2, A3 = Luas penampang } 1,2 \operatorname{dan} 3\left(\mathrm{~m}^{2}\right)
\end{aligned}
$$

\section{Hasil dan Pembahasan}

\section{a. Analisa Jaringan Distribusi Air Bersih Existing menggunakan EPANET 2.0}

Simulasi jaringan perpipaan distribusi air bersih existing di Kelurahan Harapan Baru dilakukan dengan software EPANET 2.0, dengan waktu simulasi 24 jam yang dimulai dari jam 00:00 hingga kembali ke waktu yang sama, dengan memakai data pemakaian air dalam waktu 48 jam oleh PDAM di Perumahan Grand Tamansari, Kelurahan Harapan Baru, Samarinda. Pemakaian air selama 48 jam dirata-ratakan, kemudian ditentukan faktor pengali kebutuhan air, dimana besar kebutuhan debit di jam X dibagi dengan kebutuhan air rata-rata per jamnya. Untuk faktor pengali kebutuhan air dapat dilihat pada Tabel 1.

Berdasarkan Tabel 2 bahwa jam puncak di Kelurahan Harapan Baru ialah jam 08:00, yang merupakan faktor pengali kebutuhan air tertinggi dalam 24 jam.

Berdasarkan hasil analisa jaringan existing pada jam 08:00, terdapat tujuh junction yang tekanannya di bawah kriteria pipa distribusi dari Peraturan Menteri Pekerjaan Umum No.18/PRT/M/2007 (Kementerian Pekerjaan Umum Republik Indonesia, 2007) dengan tekanan minimal sebesar $0,5 \mathrm{~atm}$, yang apabila dikonversikan ke satuan meter air menjadi 5,16 meter air, di mana junction yang dimaksud dapat dilihat pada Tabel 2.

Tabel 1. Faktor pengali kebutuhan air dalam 24 jam

\begin{tabular}{lcc|ccc}
\hline No. & Jam & $\begin{array}{c}\text { Faktor } \\
\text { pengali }\end{array}$ & No. & Jam & $\begin{array}{c}\text { Faktor } \\
\text { pengali }\end{array}$ \\
\hline 1 & $00: 00$ & $\mathbf{0 , 7 6}$ & 13 & $12: 00$ & $\mathbf{1 , 0 9}$ \\
2 & $01: 00$ & $\mathbf{0 , 7 0}$ & 14 & $13: 00$ & $\mathbf{1 , 0 1}$ \\
3 & $\mathbf{0 2 : 0 0}$ & $\mathbf{0 , 6 8}$ & 15 & $14: 00$ & $\mathbf{0 , 9 6}$ \\
4 & $03: 00$ & $\mathbf{0 , 7 1}$ & 16 & $15: 00$ & $\mathbf{1 , 0 1}$ \\
5 & $04: 00$ & $\mathbf{0 , 7 3}$ & 17 & $16: 00$ & $\mathbf{1 , 0 3}$ \\
6 & $05: 00$ & $\mathbf{0 , 8 7}$ & 18 & $17: 00$ & $\mathbf{1 , 1 5}$ \\
7 & $06: 00$ & $\mathbf{1 , 1 6}$ & 19 & $18: 00$ & $\mathbf{1 , 2 7}$ \\
8 & $07: 00$ & $\mathbf{1 , 3 0}$ & 20 & $19: 00$ & $\mathbf{1 , 1 7}$ \\
9 & $\mathbf{0 8 : 0 0}$ & $\mathbf{1 , 3 1}$ & 21 & $20: 00$ & $\mathbf{0 , 9 3}$ \\
10 & $09: 00$ & $\mathbf{1 , 2 7}$ & 22 & $21: 00$ & $\mathbf{0 , 9 0}$ \\
11 & $10: 00$ & $\mathbf{1 , 2 2}$ & 23 & $22: 00$ & $\mathbf{0 , 8 7}$ \\
12 & $11: 00$ & $\mathbf{1 , 1 0}$ & 24 & $23: 00$ & $\mathbf{0 , 7 8}$ \\
\hline
\end{tabular}

Tabel 2. Daftar junction yang tekanannya di bawah kriteria nilai tekanan

\begin{tabular}{lcc}
\hline No. & Junction & $\begin{array}{c}\text { Pressure } \\
\text { m }\end{array}$ \\
\hline 1 & Junc J22 & 5,10 \\
2 & Junc J31 & 1,96 \\
3. & Junc J57 & 4,72 \\
4. & Junc J67 & 5,15 \\
5. & Junc J74 & 1,78 \\
6. & Junc J75 & 0,77 \\
7. & Junc J76 & $-4,28$ \\
\hline
\end{tabular}

Berdasarkan Tabel 2, besar tekanan yang rendah pada tujuh junction tersebut disebabkan oleh beberapa faktor, yakni kehilangan energi atau head loss yang disebabkan oleh dinding pipa serta komponen pipa lainnya yang mengakibatkan terjadinya penurunan tekanan, elevasi pada tempat tersebut yang terlampau tinggi sehingga pada saat jam puncak tekanan tidak dapat sampai ke tempat tersebut, dan pengaturan katup yang terlalu kecil.

Selain tekanan, veriabel kecepatan air juga dianalisa, dimana terdapat sebelas pipe yang memiliki kecepatan di bawah kriteria pipa distribusi dari Peraturan Menteri Pekerjaan Umum No.18/PRT/M/2007 (Kementerian Pekerjaan Umum Republik Indonesia, 2007), yakni sebesar $0,3 \mathrm{~m} / \mathrm{s}$ di mana pipe yang dimaksud dapat dilihat pada Tabel 3 .

Berdasarkan Tabel 3 di atas, rendahnya kecepatan aliran pada pipa-pipa tersebut disebabkan oleh diameter pipa yang ukurannya terlalu besar dibandingkan dengan besar debit aliran di dalam pipa. 


\section{TEKNIK, 39 (1), 2018, 65}

Tabel 3. Daftar pipe yang kecepatannya di bawah kriteria nilai kecepatan

\begin{tabular}{ccc}
\hline No. & Pipe & $\begin{array}{c}\text { Velocity } \\
(\mathbf{m} / \mathbf{s})\end{array}$ \\
\hline 1. & Pipe P46 & 0,28 \\
2. & Pipe P47 & 0,28 \\
3. & Pipe PR1 & 0,23 \\
4. & Pipe P24 & 0,18 \\
5. & Pipe P25 & 0,18 \\
6. & Pipe P66 & 0,11 \\
7. & Pipe P67 & 0,11 \\
8. & Pipe P69 & 0,11 \\
9. & Pipe P70 & 0,11 \\
10. & Pipe P58 & 0,11 \\
11. & Pipe P59 & 0,11 \\
\hline
\end{tabular}

b. Perbandingan Hasil Simulasi EPANET 2.0 dengan Pengukuran Pelanggann pada Kran Pelanggan

Dalam penelitian ini, dilakukan perbandingan antara nilai tekanan air dari hasil simulasi jaringan distribusi existing menggunakan software EPANET 2.0 dengan nilai tekanan air hasil pengukuran di lapangan pada titik uji yang lokasinya berdekatan dengan junction pada model yang dibuat menggunakan EPANET 2.0, yang dapat dilihat pada Tabel 4 .

Tabel 4. Perbandingan antara hasil simulasi menggunakan software EPANET dengan pengukuran langsung pada kran pelanggan di Kelurahan Harapan Baru

\begin{tabular}{|c|c|c|c|c|c|}
\hline No. & $\begin{array}{c}P_{\text {lapangan }} \\
\text { (meter } \\
\text { air) }\end{array}$ & $\begin{array}{c}\text { Junction } \\
\text { terdekat } \\
\text { pada } \\
\text { model } \\
\text { EPANET }\end{array}$ & $\begin{array}{c}\text { P }_{\text {EPANET }} \\
\text { (meter } \\
\text { air) }\end{array}$ & $\begin{array}{c}\text { P }_{\text {EPANET }} \\
- \\
\text { P lapangan } \\
\text { (meter } \\
\text { air) }\end{array}$ & $\begin{array}{c}\text { Pipa } \\
\text { terdekat }\end{array}$ \\
\hline 1 & 16,005 & J24 & 29,34 & 13,335 & P29 \\
\hline 2 & 26,008 & $\mathrm{JB} 2$ & 27,77 & 1,762 & P30 \\
\hline 3 & 1,000 & J31 & 1,96 & 0,96 & $\mathrm{P} 25$ \\
\hline 4 & 2,001 & $\mathrm{~J} 32$ & 13,46 & 11,479 & P26 \\
\hline 5 & 10,003 & J36 & 18,73 & 8,727 & P32 \\
\hline 6 & 26,008 & $\mathrm{~J} 63$ & 25,79 & $-0,218$ & P56 \\
\hline 7 & 0,000 & J76 & $-4,28$ & $-4,28$ & P66 \\
\hline 8 & 0,000 & J74 & 1,78 & 1,77 & P68 \\
\hline 9 & 22,007 & J79 & 20,42 & $-1,587$ & P69 \\
\hline 10 & 22,007 & J78 & 19,43 & $-2,577$ & P68 \\
\hline 11 & 1,500 & J87 & 7,98 & 6,48 & P81 \\
\hline 12 & 8,003 & J86 & 12,36 & 4,357 & P81 \\
\hline 13 & 6,002 & J88 & 6,91 & 0,908 & P82 \\
\hline 14 & 1,000 & J57 & 4,72 & 3,72 & P52 \\
\hline 15 & 30,009 & J64 & 25,91 & $-4,099$ & P57 \\
\hline 16 & 18,006 & J52 & 27,91 & 9,904 & P50 \\
\hline
\end{tabular}

Berdasarkan Tabel 4 di atas terdapat perbedaan nilai tekanan air antara hasil simulasi model EPANET dengan pengukuran langsung pada kran pelanggan, baik yang selisihnya tidak terlalu jauh maupun yang selisihnya besar.
Faktor yang mempengauhi perbedaan antara hasil simulasi model EPANET dengan pengukuran langsung pada kran pelanggan yaitu:

a. Pengaruh faktor umur pipa yang memengaruhi koefisien Hazen-Williams

b. Adanya kemungkinan terjadinya kebocoran pada jaringan pipa distribusi yang mengakibatkan tekanan air pada saat pengukuran tekanan menjadi kecil (baik itu kebocoran halus maupun yang lumayan besar).

c. Pengaruh penggunaan air pada saat pengukuran tekanan air di jam puncak (08:00 pagi) lebih sedikit dari jumlah penggunaan air yang dimasukkan pada model EPANET

d. Adanya kemungkinan setting katup pengatur tekanan jauh lebih kecil dari data pengaturan katup yang di dapatkan.

\section{c. Rekomendasi Perbaikan Jaringan Perpipaan Distribusi Air Bersih Existing}

Setelah dilakukan analisa jaringan perpipaan distribusi air bersih existing melalui simulasi menggunakan software EPANET 2.0 dan pengukuran langsung di kran pelanggan, dapat disimpulkan bahwa pada beberapa titik masih ada tekanan air yang di bawah kriteria Peraturan Menteri Pekerjaan Umum No.18/PRT/M/2007(Kementerian Pekerjaan Umum Republik Indonesia, 2007), yakni minimal sebesar 5,16 meter air, serta pada beberapa pipa kecepatan aliran airnya di bawah kriteria dari peraturan yang sama, yakni minimal sebesar $0,3 \mathrm{~m} / \mathrm{s}$. Oleh karena itu, perlu dilakukan perbaikan pada jaringan distribusi air bersih existing, yakni:

a. pipa-pipa air yang diameternya terlalu besar akan diganti

b. katup atau valve existing akan diganti diamaternya dan atau diatur tekanannya,

c. penambahan pompa pada beberapa titik tertentu di jalan raya dengan spek yang cocok untuk dapat mendistribusikan air secara optimal hingga titik terjauh dan atau titik yang memiliki elevasi yang tinggi, terutama pada saat jam puncak, waktu dimana banyak masyarakat yang menggunakan air bersih.

Terdapat kendala yang dihadapi dalam melakukan perbaikan jaringan perpipaan, karena PDAM Tirta Kencana mempertimbangkan beberapa faktor, antara lain terbatasnya anggaran atau dana, adanya laporan atau keluhan dari pelanggan, dan kegiatan peremajaan pipa pada titik tertentu saja atau tidak secara keseluruhan.

Dengan mempertimbangkan kendala yang dihadapi dalam mengoptimalkan distribusi air bersih di Kelurahan Harapan Baru, serta strategi PDAM Tirta Kencana Kota Samarinda dalam melakukan perbaikan jaringan perpipaan distribusi air bersih, maka dari itu peneliti akan memberikan rekomendasi kepada PDAM 


\section{TEKNIK, 39 (1), 2018, 66}

Tirta Kencana dengan menyesuaikan prioritas utama perusahaan (PDAM Tirta Kencana) dalam mendistribusikan air bersih, yakni penyediaan air selama 24 jam dan tekanan air minimal 0,5 bar secara merata. Rekomendasi perbaikan dengan penyesuaian skala prioritas PDAM dapat dilihat di Tabel 5.

Tabel 5. Daftar Rekomendasi berdasarkan skala prioritas utama PDAM Tirta Kencana

\begin{tabular}{|c|c|}
\hline No. & $\begin{array}{c}\text { Rekomendasi berdasarlan skala prioritas } \\
\text { PDAM Tirta Kencana }\end{array}$ \\
\hline 1 & $\begin{array}{l}\text { Perubahan pengaturan valve VALVE11 dari } \\
\text { tekanan } 15,2997 \mathrm{~m} \text { (1,5 bar) menjadi } 20,3996 \mathrm{~m} \\
(2 \text { bar }) \text { untuk menambah tekanan pada } \\
\text { Perumahan PIMA (J57). }\end{array}$ \\
\hline 2 & $\begin{array}{l}\text { Perubahan pengaturan valve VALVE6 dari } \\
\text { tekanan } 10,1998 \mathrm{~m} \text { ( } 1 \text { bar) menjadi } 15,2997 \mathrm{~m} \\
(1,5 \text { bar }) \text { untuk menambah tekanan pada } \mathrm{Jl} \text {. } \\
\text { Cipto Mangunkusumo Gang } 2 \text {. }\end{array}$ \\
\hline 3 & $\begin{array}{l}\text { Penambahan booster pump pada pipa P61 } \\
\text { berdiameter 293,6 mm (12") di Jl. H.A.M. } \\
\text { Rifadin, tepat setelah Kampus Melati, untuk } \\
\text { menambah tekanan pada Perumahan Grand } \\
\text { Tamansari. }\end{array}$ \\
\hline
\end{tabular}

\section{Kesimpulan}

Hasil simulasi EPANET 2.0 menunjukkan bahwa jaringan perpipaan distribusi air bersih existing di Kelurahan Harapan Baru memiliki 7 junction yang nilai tekanan airnya di bawah batas minimum kriteria pipa distribusi dari Peraturan Menteri Pekerjaan Umum No.18/PRT/M/2007 (Kementerian Pekerjaan Umum Republik Indonesia, 2007) sebesar 5,16 meter air dan sebanyak 11 pipa yang nilai kecepatan aliran airnya di bawah batas minimum kriteria yang sama sebesar 0,3 $\mathrm{m} / \mathrm{s}$. Rekomendasi perbaikan jaringan perpipaan distribusi air bersih yakni penggantian ukuran diameter pipa dan valve existing, perubahan pengaturan tekanan pada valve existing sebesar 0,5 bar pada setiap pelanggan, dan penambahan pompa booster pada beberapa titik.

\section{Daftar Pustaka}

Al Amin, M. B. (2011). Komputasi Analisa Hidraulika Jaringan Pipa Air Minum. Presented in Seminar Nasional Kebumian 2011. Yogyakarta, Indonesia
Ahmadullah, R. \& Dongshik, K. (2016). Designing of Hydraulically Balanced Water Distribution Network Based on GIS and EPANET. International Journal of Advanced Computer Science and Applications, 7(2), 118-125

Hamdani, Sulistio, H. \& Syahputra, Z. (2014). Perencanaan Pipa Distribusi Air Bersih Kelurahan Sambaliung Kecamatan Sambaliung Kabupaten Berau. Teknik Sipil dan Arsitektur, 4(1), 1-9

Ibrahim, M., Masrevaniah, A. \& Darmawan, V. (2011). Analisa Hidrolis Pada Komponen Sistem Distribusi Air Bersih Dengan Waternet dan Watercad Versi 8 (Studi Kasus Kampung Digiouwa, Kampung Mawa dan Kampung Ikebo, Distrik Kamu, Kabupaten Dogiyai. Jurnal Pengairan, 2(2)

Kementerian Pekerjaan Umum Republik Indonesia (2007). Peraturan Menteri Pekerjaan Umum Republik Indonesia Nomor 18 Tahun 2007 tentang Penyelenggaraan Pengembangan Sistem Penyediaan Air Minum, http://ciptakarya.pu.go.id/dok/hukum/permen/per men_18_2007.pdf

Komalia, K. \& Indrawan, I. (2013). Analisa Pemakaian Air Bersih (PDAM) untuk Kota Pemantang Siantar, Jurnal Teknik Sipil USU, 2(2)

PDAM Tirta Kencana. (2015). Profile PDAM Tirta Kencana Kota Samarinda [powerpoint slides]. Samarinda: PDAM Tirta Kencana

Ramana, G.V., Sudheer, Ch.V.S.S. \& Rajasekhar, B. (2015). Network Analysis Of Water Distribution System in Rural Areas Using EPANET. Procedia Engineering, 119, 496-505

Selintung, M., Hatta, M.P. \& Sudirman, A. (2012). Analisa Pipa Jaringan Distribusi Air Bersih Di Kabupaten Maros Dengan Menggunakan Software Epanet 2.0. Jurnal Tugas Akhir, Makassar: Universitas Hasanuddin

Sudarsono, B. \& Nugraha, A.L. (2013). Pemanfaatan Peta Tematik untuk Analisa Kebocoran Jaringan Pipa Distribusi di PDAM Demak. Teknik, 34(3), 196-201 